\title{
Penataan Jalur Pedestrian di Distrik Heram, Kota Jayapura
}

\author{
* Maria Patricia Pearlyn, Musfira \\ Perencanaan Wilayah dan Kota, Universitas Sains dan Teknologi Jayapura \\ *mariapearlyn@yahoo.com dan fira.naja3@yahoo.com
}

\section{INFO ARTIKEL}

Riwayat Artikel:

Diterima:04-12-2020

Disetujui: 28-01-2021

\section{Kata Kunci:}

Jalur

Pedestrian

Distrik Heram

Jayapura

Pejalan kaki

\begin{abstract}
ABSTRAK
Abstrak: Jalur pedestrian merupakan wadah atau ruang untuk kegiatan pejalan kaki melakukan aktivitas dan memberikan pelayanan kepada pejalan kaki sehingga dapat meningkatkan kelancaran, keamanan, dan kenyamanan bagi pejalan kaki. Kondisi eksisting pedestrian di Distrik Heram sebagian besar pedestrian tidak berfungsi sebagai wadah untuk pejalan kaki. Pedestrian di Distrik Heram digunakan untuk pelaku aktivitas ruang publik seperti sebagai tempat parkir kendaraan, pedagang kaki lima dan pangkalan angkutan kota. Penelitian ini bertujuan untuk mengamati penataan jalur pedestrian di Distrik Heram Kota Jayapura. Metode penelitian menggunakan metode kualitatif menggunakan pendekatan deskriptif. Peninjauan langsung di lapangan dilakukan dengan beberapa pengamatan dan identifikasi secara langsung seperti Wawancara, Observasi dan kuesioner.
\end{abstract}

\begin{abstract}
Pedestrian ways are a place or space for pedestrian activities to carry out activities and provide services to pedestrians so as to improve smoothness, safety and comfort for pedestrians. Most of the existing conditions of pedestrians in Heram District do not function as a place for pedestrians. Pedestrians in Heram District are used for public space activities such as parking for vehicles, street vendors and city transportation bases. This study aims to observe the arrangement of pedestrian paths in Heram District, Jayapura City. The research method uses qualitative methods using a descriptive approach. Direct field observations are carried out with several direct observations and identification such as interviews, observations and questionnaires.
\end{abstract}

\section{A. LATAR BELAKANG}

Distrik Heram merupakan salah satu distrik yang ada di Kota Jayapura. Jalur pedestrian merupakan wadah atau ruang untuk kegiatan pejalan kaki melakukan aktivitas dan memberikan pelayanan kepada pejalan kaki sehingga dapat meningkatkan kelancaran, keamanan, dan kenyamanan bagi pejalan kaki. Kota Jayapura memiliki jalur pedestrian kategori tingkatan C dengan lebar 100-140 cm. Secara administrasi Distrik Heram juga merupakan bagian dari Kota Jayapura Distrik Heram terbagi menjadi 3 Keluharan dan 2 Kampung yaitu Kelurahan, Waena, Kelurahan Yabansai, dan Kelurahan Hedam, sedangkan 2 kampung yaitu antara lain Kampung Yoka dan Kampung Waena serta 147 RT, dan 44 RW. Jalur Pedestrian yang di jadikan sebagai objek penelitian di Distrik Heram adalah jalur pedestrian yang ada di sepanjang jalan raya Sentani-Abepura, mulai dari Terminal Expo - Traffic lights Waena dengan jarak $\pm 350 \mathrm{~m}$.
Pada distrik ini memiliki banyak aktivitas publik dan penggunaan lahan yang beragam. Kondisi eksisting pedestrian di Distrik Heram sebagian besar pedestrian tidak berfungsi sebagai wadah untuk pejalan kaki. Pedestrian di Distrik Heram digunakan untuk pelaku aktivitas ruang publik seperti sebagai tempat parkir kendaraan, pedagang kaki lima dan pangkalan angkutan kota. Selain fungsi yang tidak sesuai, kondisi pedestrian di Distrik Heram juga belum memadai dalam arti banyak pedestrian yang rusak dan tidak didukung dengan kelengkapan sarana prasarana jalur pedestrian sehingga kurangnya peminat pejalan kaki dalam menggunakan jalur pedestrian.

Permasalahan dominan yang terdapat pada Distrik Heram yang merupakan pusat kegiatan kota yaitu jalur pedestrian yang tidak memadai seperti tidak adanya fasilitas pendukung dan tidak layaknya keadaan fisik jalur pedestrian itu sendiri, sehingga kurang maksimalnya fungsi dan kenyamanan jalur pedestrian tersebut. Jalur pedestrian yang baik sangat dibutuhkan bagi pengguna terutama pejalan kaki dalam melakukan aktivitasnya ditunjang 
dengan penataan elemen-elemen pada pedestrian sehingga membuat pengguna merasa nyaman dan aman dalam melakukan aktivitasnya di jalur tersebut. Selain elemen pendukung pada pedestrian hendaknya jalur yang bisa dikatakan nyaman dan aman adalah adanya pemisahan antara pedestrian dan jalur kendaraan bermotor.

Kegiatan ekonomi yang berada pada Distrik Heram dapat mengundang pelaku-pelaku aktivitas di ruang publik lain yang memanfaatkan hilir mudik pejalan kaki. Pelaku aktivitas ruang publik tersebut menempati sebagian badan jalan sebagai tempat parkir kendaraan, berjualan pedagang kaki lima, pangkalan taxi, angkutan kota dan tempat berkumpul atau berosialisasinya klub otomotif atau pengguna yang sekedar menghabiskan waktu. Jalur pedestrian di sekitar Distrik Heram selain digunakan sebagai wadah sirkulasi pejalan kaki juga digunakan sebagai tempat pedagang kaki lima berjualan dan parkir kendaraan bermotor. Sebagian besar kegiatan pedagang kaki lima ini berlangsung dari mulai pagi hingga malam. Jalur pedestrian yang ada di Distrik Heram juga belum memenuhi syaratsyarat pedestrian yang baik. Dari segi ukuran, yakni lebar jalur pedestrian yang ada di Distrik Heram adalah $140 \mathrm{~cm}$, dan memiliki tinggi dari permukaan jalan yang bervariatif, mulai dari $30 \mathrm{~cm}-50 \mathrm{~cm}$. Jalur pedestrian di Distrik Heram juga tidak terdapat pohon peneduh dan bangku untuk beristirahat. Berdasarkan hasil survey dapat disimpulkan bahwa elemen pelengkap pedestrian di Distrik Heram belum sesuai dngan standar pedestrian perkotaan sehingga pejalan kaki kurang berminat menggunakan pedestrian dan fungsi pedestrian tersebut berubah sebagai tempat PKL dan parkir. Oleh sebab itu, pada penelitian ini penulis hendak menata jalur pedestrian Di Distrik Heram dengan melihat kelengkapan pedestrian (street furniture) untuk menarik minat pengguna pedestrian.

\section{B. METODE PENELITIAN}

Penelitian ini tergolong jenis penelitian deskriptif yang bertujuan untuk mendiskripsikan penataan jalur pedestrian untuk menarik minat pejalan kaki di Distrik Heram Kota Jayapura.

\section{Lokasi Penelitian}

Lokasi penelitian berada di Kota Jayapura yaitu di Distrik Heram.

\section{Teknik Pengumpulan Data}

Data penelitian yang digunakan didapat melalui studi literatur, survey/ pengamatan langsung dan wawancara pada masing-masing kategori berupa :

- Studi literatur, yaitu mengumpulkan dan mengkaji data sekunder melalui literatur-literatur yang tersedia berupa buku atau laporan-laporan penelitian sebelumnya dari berbagai instansi yang dianggap relevan dan infomasi pada jaringan Internet.

- Observasi dan survey lapangan, dilakukan untuk mendapatkan data primer dan mengamati secara langsung objek penelitian melalui :

a. Pengamatan langsung dilapangan untuk memperoleh informasi lebih lanjut mengenai kondisi eksisting jalur pedestrian di Distrik Heram

b. Dokumentasi untuk memperlihatkan secara visual kondisi jalur pedestrian.

- Wawancara, menggali informasi secara mendalam dari narasumber atau informan yang dapat memberikan informasi dan data yang diperlukan yaitu berupa keterlibatan instansi terkait terhadap pemeliharaan jalur pedestrian dan permasalahan lainnya yang berkaitan dengan penataan jalur pedestrian.

\section{Alat Bantu Penelitian}

Alat bantu yang digunakan dalam melakukan penelitian terdiri dari :

- Tinjauan pustaka, sebagai kerangka berfikir dalam mengarahkan penelitian.

- Media cetak, untuk pengumpulan informasi dan teori yang relevan untuk melihat obyek yang akan diteliti.

- Alat tulis dan elektronik (camera, alat perekam, GPS) untuk pengumpulan data dilapangan dan membuat laporan penelitian.

\section{HASIL DAN PEMBAHASAN}

\section{Gambaran Umum Lokasi}

Kota Jayapura terletak antara $137^{\circ} 27^{\prime}-141^{\circ} 41^{\prime}$ Bujur Timur dan $1^{\circ} 27^{\prime}-3^{\circ} 49^{\prime}$ Lintang Selatan. Kota Jayapura memiliki luas 940 km2dibagimenjadi5distrikyaituDistrikJayapuraUta ra,Jayapura

Selatan,Abepura,HeramdanMuaraTami,yangterbagi atas25Kelurahandan14 Kampung, dan memiliki jumlah penduduk (288.7 86) jiwa/tahun 2019.

Penduduk Kota Jayapura tahun 2019, tercatat sebanyak 288.786 orang atau bertambah $1,87 \%$ dari tahun sebelumnya.

\section{Pedestrian di Distrik Heram}

Berdasarkan Pedoman Tata Cara Perencanaan Fasilitas Pejalan Kaki di Kawasan Perkotaan Departemen PU (1995) dapat dijelaskan, pedestrian ways atau jalur pejalan kaki adalah jalur yang disediakan untuk pejalan kaki guna memberikan pelayanan kepada pejalan kaki sehingga dapat meningkatkan kelancaran, keamanan, dan kenyamanan pejalan kaki tersebut. Zona pejalan kaki (pedestrian) adalah area yang diperuntukkan untuk jalur pejalan kaki. Zona pejalan kaki terdiri dari beberapa bagian yaitu zona bagian depan gedung, zona penggunaan bagi pejalan kaki, zona tanaman/perabot, dan zona pinggir jalan (Pedoman Penyediaan dan Pemanfaatan Prasarana dan Sarana 
Ruang Pejalan Kaki di Perkotaan Dept.PU, 2012). Dengan demikian, dapat disimpulkan bahwa pedestrian ways/ jalur pejalan kaki adalah area berupa jalur yang digunakan oleh pejalan kaki sebagai penghubung dalam melakukan suatu aktivitas di suatu lokasi.
2. Jalur pejalan kaki sebaiknya ditempatkan jauh dari lalu lintas kendaraan sehingga keamanan pejalan kaki lebih terjamin, serta tersedianya prasarana pemberhentian bus dan dekat dengan prasarana umum lainnya.

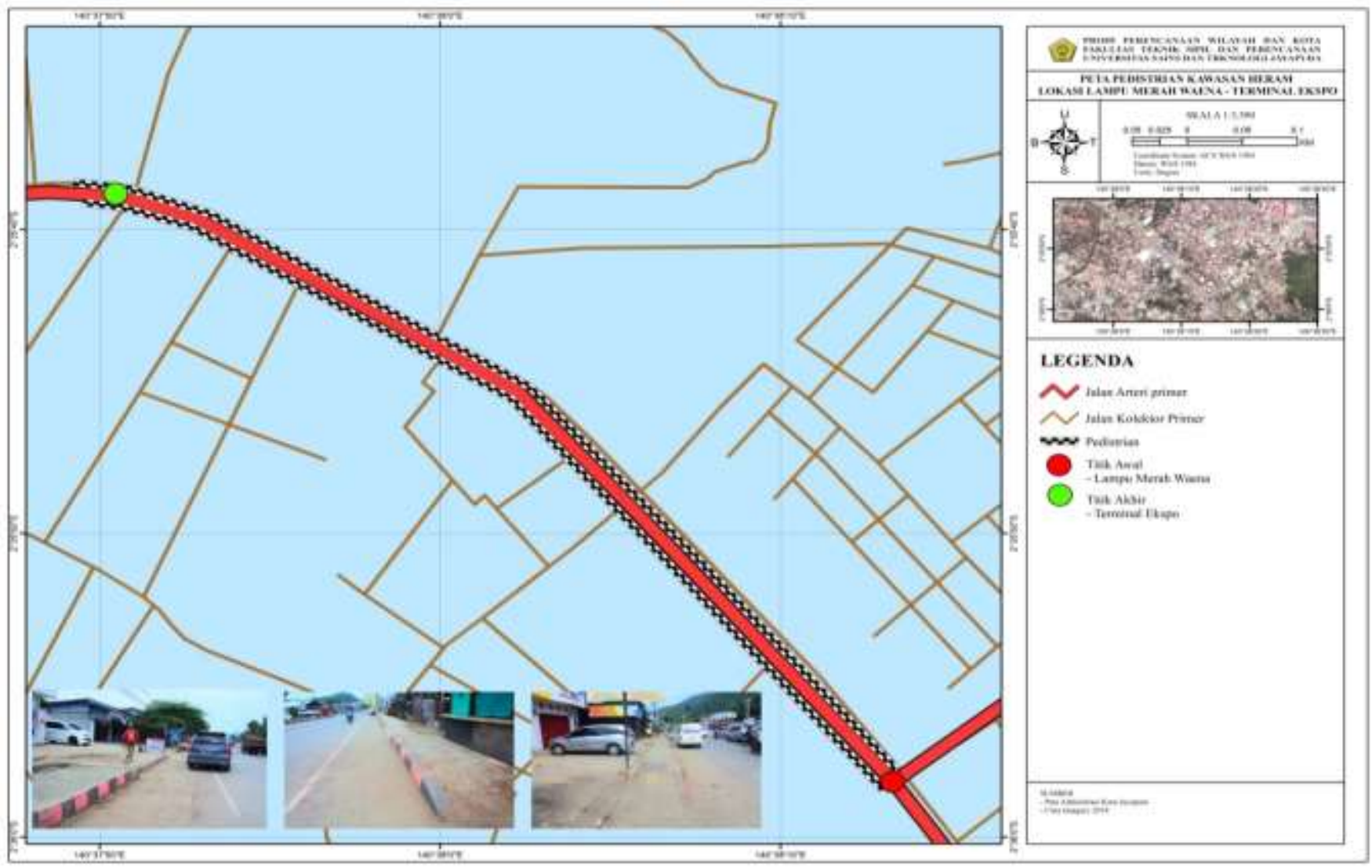

Gambar 1.Peta Pedesterian Kawasan Heram

Pedoman Penyediaan dan Pemanfaatan Prasarana dan Sarana Ruang Pejalan Kaki di Perkotaan, Dept. PU (2012) dapat dijelaskan, ada 5 tipologi Ruang Pejalan Kaki, yaitu:

1. Ruang Pejalan Kaki di Sisi Jalan (Sidewalk).

2. Ruang Pejalan Kaki di Sisi Air (Promenade).

3. Ruang Pejalan Kaki di Kawasan Komersial/ Perkantoran (Arcade).

4. Ruang Pejalan Kaki di RTH (Green Pathway).

5. Ruang Pejalan Kaki di Bawah Tanah (Underground).

Melihat dari pedoman di atas maka dapat ditarik kesimpulan bahwa pedestrian di lokasi penelitian termasuk tipologi Ruang Pejalan Kaki di Sisi Jalan dan Ruang Pejalan Kaki di Kawasan Komersial/Perkantoran.

Pedoman Teknik Persyaratan Aksesibiltas pada Jalan Umum (Departemen Pekerjaan Umum tahun 1999) dapat dijelaskan, persyaratan teknik penerapan prasarana aksesibilitas dibagi menjadi: Prasarana Aksesibilitas pada Jalur Trotoar/ Jalur Pejalan Kaki. Persyaratan teknik yang harus diperhatikan dalam perencanaan jalur pejalan kaki adalah:

1. Tingkat kenyamanan pejalan kaki yang optimal, seperti an dan jarak tempuh serta rambu-rambu petunjuk pejalan kaki.
3. Keamanan terhadap kemungkinan terjadinya benturan antara pengguna jalur pejalan kaki, terutama bagi penyandang cacat berkursi roda.

4. Penerangan yang cukup di malam hari sehingga memungkinkan jarak pandang yang cukup.

5. Hindari terjadinya hambatan-hambatan dan ketidaknyamanan berjalan kaki yang disebabkan oleh adanya pedagang kaki lima pada jalur pejalan kaki.

6. Jalur pejalan kaki dibuat sedemikian rupa sehingga pada waktu hujan permukaannya tidak licin dan tidak terjadi genangan air serta disarankan untuk dilengkapi dengan pohon-pohon peneduh pada jalur tepinya.

7. Drainase sebaiknya dibuat tegak lurus dengan arah jalan dengan lubang yang dijauhkan dari tepi jalur penghubung (ramp) sehingga tidak mendatangkan bahaya.

8. Tepi jalur penghubung (ramp) dan batas pegangan (hand railing) bagi tongkat tuna netra. Penting adanya tepi jalur penghubung (ramp) untuk penghentian roda bagi pemakai kursi roda dan pegangan (hand railing) bagi tongkat tuna netra kea rah daerah yang berbahaya. Penyetop dibuat setinggi 
minimum $0,1 \mathrm{~m}$ dan lebar 1,5 $\mathrm{m}$ sepanjang jalur pejalan kaki.

Perencanaan Jalur Pejalan Kaki, lebar standar (dimensi/ukuran pedestrian ways), untuk mengetahui

$$
\mathrm{W}=\frac{\mathrm{v}}{35}+\mathrm{N}
$$

Keterangan:

$\mathrm{W}=$ lebar trotoar (meter)

$\mathrm{V}=$ volume pejalan kaki rencana/ dua arah (orang/ meter/menit)

$\mathrm{N}=$ lebar tambahan sesuai dengan keadaan setempat (meter)

Volume pejalan kaki (V) didapat dengan melakukan pengamatan pada lokasi penelitian. Pencatatan dilakukan setiap interval 15 menit selama enam jam paling sibuk dalam satu hari. Karena keterbatasan SDM, maka data $\mathrm{V}$ diasumsikan selama 15 menit pejalan kaki yang melewati trotoar tersebut adalah 4 orang.

15 menit $\mathrm{V}=4$ orang/ meter/menit

60 menit $\mathrm{V}=16$ orang/ meter/menit

360 menit $\mathrm{V}=96$ orang/ meter/menit

Lebar tambahan (N) berdasarkan Petunjuk Perencanan Trotoar No.007/T/BNKT/1990 Direktorat Pembinaan Jalan Kota adalah

Tabel 1

\begin{tabular}{cc}
$\mathbf{N}$ (meter) & Ukuran Lebar Tambahan \\
Keadaan \\
\hline 1,5 & Jalan di daerah pasar \\
1,0 & Jalan di daerah perbelanjaan bukan pasar \\
0,5 & Jalan di daerah lain \\
\hline
\end{tabular}

Dari tabel di atas, digunakan $\mathrm{N}=1$ meter, sehingga $\mathrm{W}==3,7$ meter. Berdasarkan perhitungan di atas, lebar trotoar (W) yang sesuai standar ideal pada lokasi penelitian adalah 3,7 meter. Sedangkan berdasarkan pada Petunjuk Perencanaan Pedestrian, lebar minimum pada penggunaan lahan perkantoran, terminar, pertokoan/perbelanjaan adalah 2 meter. Seperti yang ditunjukkan pada tabel di bawah ini.

\section{Tabel 1}

Lebar Minimum Trotoar Menurut Penggunaan Lahan

\begin{tabular}{lc} 
Penggunaan Lahan sekitarnya & Lebar minimum (m) \\
\hline 1. Perumahan & 1,5 \\
2. Perkantoran & 2,0 \\
3. Industri & 2,0 \\
4. Sekolah & 2,0 \\
5. Terminal/ Stop Bus & 2,0 \\
6. Pertokoan/ Perbelanjaan & 2,0 \\
7. Jembatan/ Terowonoan & 1.0
\end{tabular}

Berdasarkan hasil analisa di atas dengan cara mengkomparatifkan antara standar PU dan kondisi eksisting diketahui bahwa lebar pedestrian tidak memenuhi standar. Sehingga dapat disimpulkan lebar standar pedestrian ways, dalam hal ini adalah trotoar/side walk, digunakan rumus:
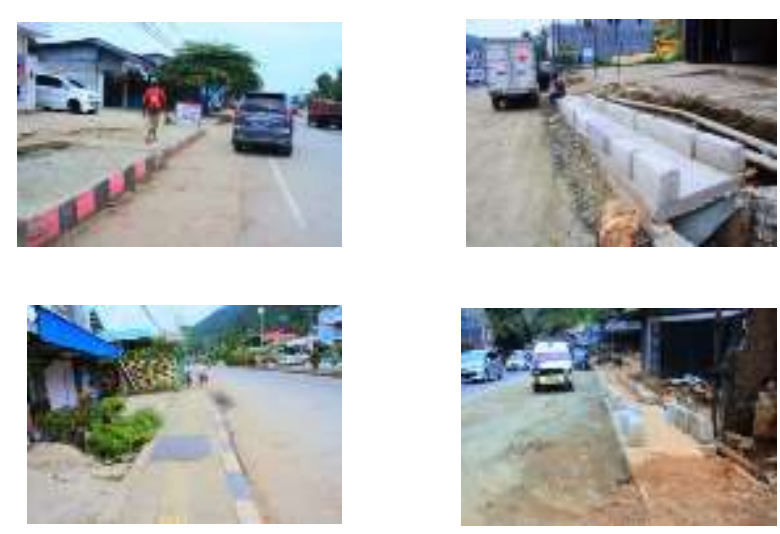

Gambar 2. Kondisi Eksisting Pedestrian di Distrik Heram

bahwa Pedestrian di Distrik Heram belum sesuai standar. 
[1] Feybe G.Kaliongga, 2014. Kajian Aspek Kenyamanan Jalur Pedestrian Jl. Piere Tendean di Kota Manado, Sabua Vol.6, No.2: 243-252, Agustus 2014

[2] Pradana, Antonio Heltra, Ernawati, Jenny, Martiningrum, Indyah.2016. WalkabilityJalur Pedestrian by Design di Area Kampus Universitas Brawijaya, Malang. Malang: Jurusan Arsitektur, Fakultas Teknik, Universitas Brawijaya.

\section{KESIMPULAN DAN SARAN}

\section{a. Kesimpulan}

Berdasarkan hasil analisa dan pembahasan yang telah dilakukan, maka dapat disimpulkan bahwa:

1. Berdasarkan standar lebar minimum trotoar dan perhitungan lebar trotoar ideal, maka disimpulkan trotoar/ jalur pedestrian yang ada di Distrik Heram tudak memenuhi standar.

2. Berdasarkan observasi dan survey lapangan yang dilakukan dapat disimpulkan bahwa street furniture yang ada pada jalur pedestrian di Distrik Heram tidak memadai. Hal ini juga akan berpengaruh pada minat pejalan kaki.

3. Lahan pedestrian yang ada pada saat ini pada dasarnya sangat mencukupi untuk dilakukan penataan yang sesuai standar apabila di design dengan baik dan sesuai dengan karakteristik pengguna jalur pedestrian.

\section{b. Saran}

Dari kesimpulan yang diuraikan di atas, penulis mengemukakan beberapa saran yang diharapkan dapat memberikan implikasi yang bermanfaat baik secara teoritis maupun secara empiris, sebagai berikut :

1. Upaya perencanaan jalur pedestrian serta seluruh elemen pelengkap pedestrian yang baik di Distrik Heram maka perlu direncanakan serta perlu diperhatikan setiap elemen yang rusak seperti lampu jalan, tempat sampah, tempat di Kota Jayapura, agar kenyamanan bagi pengguna pedestrian terjaga dengan baik.

2. Jalur pedestrian di Kota Jayapura harus difungsikan sebagaimana fungsinya agar dan harus ada perhatian khusus bagi Pemerintah Daerah setempat untuk memperhatikan hal ini, seperti kurangnya minat pejalan kaki karena adanya aktifitas lain yang dilaksanakan pada jalur pedestrian.

3. Jalur Pedestrian di Distrik Heram secara garis besar belum memadai dan butuh perhatian pemerintah untuk memperhatikan dan memperbaiki setiap elemen jalur pedestrian yang rusak dan yang belum ada.
[3] Pattisinai, 2013 Faktor-faktor yang mempengaruhi jarak tempuh pejalan kaki

[4] Kusbintoro, 2007. Elemen jalur pedestrian.

[5] Pedoman Penyediaan dan Pemanfaatan Prasarana dan Sarana Ruang Pejalan kaki di Perkotaan. 2012. Direktorat Peanaat Ruang Departemen Pekerjaan Umum. 